\title{
Yemeni EFL Learners' Identity Conflicts: An Exploratory Case Study
}

\author{
Rais Ahmed Attamimi ${ }^{1}$, Nasser Omer M. Al-Tamimi ${ }^{2}$ \& Jon Andrew Chittick ${ }^{1}$ \\ ${ }^{1}$ English Language Center, Salalah College of Technology, Sultanate of Oman \\ ${ }^{2}$ Department of English, College of Education, Seiyun University, Yemen
}

Correspondence: Rais Attamimi, North Sa'ada, Salalah, Dhofar Governorate, Oman. E-mail: rais_attamimi@yahoo.com

Received: March 19, 2019 Accepted: April 15, 2019 Online Published: May 8, 2019

doi:10.5539/ijel.v9n3p268 URL: https://doi.org/10.5539/ijel.v9n3p268

\begin{abstract}
The importance of the concept of "identity" in the context of language learning is unassailable. Stemming from this premise, the current study is intended to explore the identity conflicts of a group of Yemeni learners who were studying English, as well as the techniques and strategies used to mitigate and/or lessen the conflicts between their actual identity and the identity associated with the target language, i.e., English. This research project used a qualitative exploratory case study research design with a sample of 20 students who were requested to write their journal diaries. Following that, semi-structured interviews were conducted using the double-sampling technique to select 10 of the previously sampled students who were proven to have written the most stimulating and intriguing journal entries. From the results of the study, tangible identity conflicts between the Yemeni culture and society at large and the implied behaviors and conventions accompanying the intensive study of the English language became apparent. The students exhibit a high level of motivation and they also exert their efforts using different techniques and strategies to excel at the learning and/or acquisition of the speaking skill of the English language. These conflicts may be consciously or subconsciously realized by the language learners, but what has been proven is that their attitudes, motivation and general inclinations towards the goal of speaking with a native or a native-like accent are unquestionably genuine. Lastly, the study suggested or recommended a revamp of the current textbooks giving teachers more training sessions in order to improve their individual repertoire, as well as a higher degree of awareness upon the part of the Yemeni society at large that these conflicts can interfere with the strong motivations, both aspirational and actual, to achieve the learning outcomes of the nation's most promising future leaders and pioneers.
\end{abstract}

Keywords: identity, conflicts, language, learning, motivation, investment, imagined communities, Hadhramout

Identity is your uniqueness shining like the sun's rays through the dark clouds of society.

(Salazar \& Reyes, 2015)

\section{Introduction}

The Middle Eastern nation of Yemen has drawn a riveting degree of attention in recent times due to the unfortunate conflicts that have afflicted the daily lives of its beleaguered citizenry. In spite of these circumstances, educational endeavors combined with the heartfelt desire of learners to participate in and achieve desirable outcomes based upon different levels of motivation have kept teaching methods and prerogatives at least somewhat in the spotlight of educational research. Turning to the geographical outpost of the Hadhramout Valley and Desert Region, itself a part of the Hadhramout Governorate, it is possible to ascertain the circumstance that Yemeni students seem to have a generally strong impulse to learn English, as well as to exert all their energies into making their current lives better (Attamimi \& Abdul Rahim, 2011). Succinctly stated, this study established that Yemeni students are motivated to learn the English language based upon their internal incentives and their social, economic, and cultural backgrounds.

It has been demonstrated that, in spite of the several varieties of social and economic stratification that prevails, the students appear to exhibit comparatively high levels of motivation in which to integrate themselves and to learn English within a group of speakers who can then go on to procure high-paying jobs in the oil and petroleum industries upon graduating from their educational institutions. The underlying process involves the 
mental reconstruction of possible self-identities as they imagine, or visualize, themselves as being in the circle of elite Yemeni English speakers (Ibid).

\subsection{Statement of the Problem}

The English language in Yemen, as in many other nations around the world, is officially regarded as a foreign language. To wit, students in Yemen effectively use English only within the confines of a physical classroom, and nowhere else. Practically speaking, there is no natural outlet or opportunity for these students to extend their English language study to physically or naturally occurring locations within their immediate geographical settings. Above and beyond these considerations, it is also true that these students exhibit multiple identities, ranging from social to cultural identities. It has been observed that, though students have a strong internal motivation to learn English as a second language (Attamimi \& Abdul Rahim, 2011), there remain several inherent conditions, ranging from tribal to religious and linguistic identities, that will instigate conflict with their concurrent use and practice to make English as a target language to master. This observation can be most clearly corroborated when these students are observed in their attempts to speak English (Al-Tamimi \& Attamimi, 2014, 2018). In most cases, any semblance of non-verbal awareness in the act of speaking English appears to be non-existent. Students commonly speak in monotones; make no attempt to vary the pitch or speed of the words that they utter, and do not observe the natural impulses to separate any one of their spoken ideas from another, blurting out all of their words in an unending string of enunciation that sounds vaguely meaningless (Ibid).

\subsection{Objectives}

This study investigated the multiple identities and the conflicts resulting from them in the process of learning English as a foreign language in the Yemeni context. To this end, the study has focused on achieving the two following objectives:

1) To explore the identity conflicts exhibited by the Yemeni English learners, in terms of their beliefs and actions. Their beliefs will be exhibited in their multiple identities, and their actions will reflect upon the manner in which they speak the target language;

2) To identify the strategies and techniques the students use to mitigate the adverse effects of the conflicts arising from their beliefs and actions.

\section{Theoretical and Conceptual Background}

In order to familiarize the reader with the main concepts framed as the theoretical basis for the current study, factors such as identity, motivation, investment, and imagined communities or imagined identities are discussed in the following pages.

\subsection{Identity in L2 Learning Context}

Identity of learners is a new concept which has been given much attention recently by foreign language (FL) as well as second language (SL) researchers. It is defined by sociocultural theory proponents as a complex, contradictory and multi-faceted phenomenon. It is also defined as being dynamic in its effect on language learners, and can be changed across wide intervals of time and far-flung outposts of geographic place. It is also negotiated, constructed, conflicted and susceptible to different political and cultural influences of the relationship to power (Norton, 2006; Ramanathan \& Pennycook, 2008). Given all of these potentials, it has morphed into a burning issue within the domain of L2. Stemming from this fact, much associated work has been done in the 1970s as well as the 1980s which has viewed identities not only as students' fixed personalities, but also students' learning styles and motivation levels. More recently, Norton (2000) defined language learners' identities as fluid, context-dependent and context-producing. She further explained that identity is "how a person understands his or her relationship to the world, how that relationship is constructed across time and space, and how the person understands possibilities for the future" (p. 5). Therefore, identity is important in shaping the participation of individuals in a community and shaping what we do and how we do it in this community (Wenger, 1998). Participation of learners in a community is not merely taking place in a new culture setting but is also moving along to assume a crucial role in the personal struggle on the part of learners to reconstruct themselves (Pavlenko \& Lantolf, 2000). Based on this, understanding identity is an integral component to be considered by language researchers in their general quest to understand language learners' participation in using the target language in a community.

\subsection{Motivation and Investment}

Motivation can be defined as a primarily psychological construct (Dörnyei, 2001) while investment is defined as a sociological construct. These two constructs complement each other (Norton, 2013). Motivation is considered 
as a fixed characteristic of language learners. Previous researchers have assumed that a learner who has failed to learn a language has no motivation or desire to learn that language. Such researchers were not concerned with the possibility of power relationships between language learners and target language speakers. A language learner may have a high motivation towards learning a language but simultaneously he/she has correspondingly little investment in practicing the language inside the classroom or in the community he/she lives in. The learner who makes the most basic and limited degree of investment, that of the expenditure of personal time, for language practice is probably considered enough to be a motivated learner, at a more traditional and conventional level of analysis. This notion of investment as it is strongly related to motivation has been supported by Cummins (2006) by saying that investment is an important construct in language learning and teaching environments.

\subsection{Imagined Communities/Imagined Identities}

Vygotsky (1978) stated that imagination plays an important role in developing learners' language learning. Similarly, the works of Simon (1992) have confirmed that imagination is a construct that helps learners choose what type of practices are worth the time in which to dedicate and immerse themselves and their attention, in order to achieve their desired outcome or the expected vision of community they would like to reside in in the future.

To highlight the notion of imagination and imagined communities proposed by Anderson (1991), Norton (2001) clearly demonstrated that non-participation of language learners in the language classroom is due to the discrepancy between learners' imagined communities and the aim of pedagogy employed by the teacher and the students' investment in the target language. This relationship is attached to the imagined communities that language learners want to join in the future.

\subsection{More Related Studies}

Moná and Rodríguez (2017) examined the way Colombian students in grade seven learned their language and constructed their identities in the classroom in an EFL setting at a public school in Bogotá. The data of students' behavior and identity were collected using field notes. The students' social statuses were obtained using both a questionnaire and a set of personal interviews. All the collected data of Moná' and Rodríguez's study were analyzed from the point of a social perspective according to Norton's theoretical principles. Findings revealed that participants were unwilling to participate in the classroom due to social factors such as their socioeconomic situation, academic and family demands, and other complications due to social or cultural natures in the classroom. As a result of these social factors, it was evident that those students invested poorly, or made no investments at all; inside the classroom, even though they had sufficient motivation to invest their time and a certain amount of effort, they could not overcome their inevitably occurring social conflicts in the learning process.

Duo and Su (2015) investigated learning motivation and self-identity changes of Taiwanese college English majors. Their study was set to determine the correlation between learning motivation and self-identity changes of the students. A total of 231 Taiwanese English majors in the department of English were involved in the study. Data were collected using the adapted questionnaire from Gardner's (2004) Attitude/Motivation Test Battery (ATMB) and $\mathrm{Xu}$, as well as Gao's questionnaire. Students' self-identity changes were evaluated through using Gao's Self-identity Change Questionnaire (2011). Findings showed that students obtained a significant transfusion of high motivation towards learning English while enrolled in their academic program. The most significant of the observed change of students was in their individual levels of self-confidence. Statistically significant results were found in the correlation between motivation and self-identity changes. The researchers hoped that the results of their study would provide a deeper understanding of the students' motivation towards English and their identity construction within an EFL context.

Yoshida (2013) conducted a study to investigate Japanese language learners' conflicts between their beliefs and actions at the actual time when they speak the target language in the classroom. She also traced how these students become able to overcome their conflicts by changing their beliefs. Data were collected by using several research instruments including diary writings, interviews, and classroom observations and recordings. The findings of the study indicated that students had two different beliefs which were the importance of accuracy and the importance of participation in classroom. These two beliefs were held to be in conflict with the action of practicing these beliefs inside the classroom. The results also show how students can potentially succeed in overcoming the challenges made apparent from the learning process by confronting, consciously or otherwise, their standing set of beliefs, and develop new ones and change their actions accordingly.

Alaei and Ghamari (2013) investigated the relationship between EFL learning and national identity for a group 
of Iranian students. They also tried to find out the relationship patterns between the types of language motivation and national identity. Gender and age were included as variables to be examined in their study. A number of 350 undergraduates, who studied at Allameh Tabataba'i University in Tehran, were involved as a sample. The data were collected by using two questionnaires, one for collecting the data regarding national identity, while the other questionnaire was used to measure the different types of language learning motivation. Personal interviews were also used to cross-validate other research data instruments. Accordingly, data were analyzed using linear regression tests, an independent sample t-test and a one-way ANOVA analyzes. The findings indicated that the social effects of EFL learning have led merely to statistically insignificant outcomes. Additionally, the results revealed that "going abroad" and "social responsibility" as the types of language motivation were strongly correlated with national identity. Gender and age exhibited remarkable significant differences among all of the participants in the study. The study recommended that syllabus designers should pay attention to the demographic variables for the sake of the ability to create a contemporary and appropriately developing EFL learning program.

Gómez (2012) conducted a study in which he aimed at identifying and analyzing multiple identities that students construct when learning English as an FL. The researcher also tried to find out whether the process of identity construction has had any effect on university students' language learning outcomes. Data were collected using observational methods. The researcher composed the transcripts of oral interactions undertaken in the classroom in addition to conducting the personal interviews with the students. The findings showed that the use of the first language in the learning process inside the classroom along with the introduced conception of language learning and teaching by the teacher have constituted the most significant elements in the struggle of students and the time they have personally chosen to invest the target language and to construct their social and individual identities as learners.

Yihong et al. (2005) investigated self-identity changes related to English learning of college students in China. A sample of 2,278 undergraduates from 30 universities participated in the study. Data were collected by using a questionnaire composed of six categories related to self-identity changes. The findings of the study showed that self-confidence is the most prominent construct that influences students' attitudes about their own identities. Self-confidence was viewed as an outcome of the process of English learning. The results also indicated the significant effects of gender, age, college major, and level of English proficiency on identity changes.

\section{Methods}

\subsection{Design of the Study}

The current study is considered to be an exploratory piece of qualitative research in nature. The study is intended to explore the identity conflicts exhibited by the Yemeni English learners as well as to identify the strategies and techniques the students use to mitigate the adverse effects of the conflicts arising from their beliefs and actions. In order to optimally achieve this stated aim, a case study research design was employed to collect the data required to answer the research questions. The choice of this design was based on a set of rationales. First, the study was exploratory in nature as it sought to explore the phenomenon of identity conflicts exhibited by the EFL Yemeni English learners and the strategies employed by them to alleviate the effects of those conflicts, where no data was available about this phenomenon at the time this study was being conducted. Second, such a case study design was deemed to be appropriate as it would help us gain more in-depth information on the topic under study and would inevitably widen our understanding of the phenomenon (AlYafaei \& Attamimi, 2019).

The selected participants from the sample are undergraduate EFL majors studying at the college of Education of Seiyoun University in Yemen. They came from the same social environment and also share the same culture and religion. They are also homogenous with regard to their first language and they had previously studied English for 6 years at elementary and secondary schools. They range in age from 19 to 23 . However, they had been chosen from different college class designations of the Bachelor degree program.

This study utilized two research methods to elicit the data sought, relevant to answer the research questions and to achieve the objectives posed in the research: the diaries which were completed by the selected students, and subsequently followed up by semi-structured interviews. The study lasted for one month. At the end of each week of the four consecutive weeks of the calendar month over which the study was conducted, the students were asked to respond to several different questions in order to explore their internal identity conflicts, and the actions that typically resulted from these conflicts inside, and potentially outside, the classroom. Furthermore, additional questions were added for the purpose of better identifying the techniques and strategies used by students to lessen the conflicts they encountered while speaking the English language. 


\subsection{Research Instruments}

The semi-structured interviews were conducted in a cumulative fashion, at the end of the month of the study, and based on previous analyses of the recorded diary writings by the participants, to further comprehend, within more specific and academic research contexts, the possible answers to the issues under study. Within the initial group of 20 students, 10 students were specifically selected to be personally interviewed, based upon the nature of the responses of the diaries submitted, as their responses proved to be more informative and insightful. Interestingly enough, it happened to be the case that seven of the final ten selected participants were female. In and of itself, this circumstance, while being worthy of future research efforts, does not affect the outcomes of the current study, and should therefore not be taken into account as a significant variable. Every individual interview lasted for approximately 10 minutes. As the name suggests, the semi-structured interview allows researchers of the present study to spontaneously add further questions as the situational need arises. This assists researchers in cross-validating the data collected from the diverse array of writing and details given by the students in their general diary writing.

\section{Findings}

The perceived English-speaking skills proficiency of students revealed by their answers to some of the questions in the interviews and their diaries have interestingly revealed the learners' identity conflicts and the strategies used to mitigate them. In spite of the difficulties Yemeni students face in learning English as an FL, they have perceived themselves to be as hardworking and diligent as any other learners within any other context due to their efforts in spending much time listening and practicing their English in an environment which is not encouraging. The following findings of the writing diaries and the semi-structured interviews have specified and highlighted and/or spotlighted the challenges students face prior to and particularly during their college time in developing, most importantly, their speaking skill and what strategies they are using in order to overcome the challenges they are encountering.

\section{\#Case one: Shakira}

Shakira may be classified as a college junior, majoring in English. In the interview, as well as her diary writing, Shakira has participated in the interview with a high degree of enthusiasm, and was capable of relating her reflections and concerns fluently and spontaneously. She was really interested in writing about her experience with regard to her self-perception of her speaking skill. She is a confident speaker. She started loving the English language when she was at her high school and her mother encouraged her to learn it. She took some courses in the English language and eventually she joined the English department at the College of Education of Seyioun University, Hadhramout, Yemen. She has improved her speaking competency by watching movies and listening to different English conversations. She is always fond of imitating native speakers' pronunciation. She faced some difficulties in practicing her speaking skill within her immediate setting as she is not being surrounded by any speakers of the English language. To quote her directly, “...I feel more interested to integrate by myself with people who speak the English language in countries such as the United Kingdom and the United States of America. She has commented on her latter point by saying that "in a conservative society like Yemen, I find (it) [sic] very hard to imitate foreigners when they speak their language and that is why I have sometimes to abstain from doing that when I am with my family...". In order to overcome her challenges, she has tried to create her own environment to practice speaking English. She further added that "...most of my time I spend in talking to myself. I tried to record myself and then I listen to what I have said to correct myself. Sometimes, I speak English in front of a mirror and I imagine that I am talking to another person and make a dialogue of my own."

In her response to the open-ended question in which the students were asked to reveal their opinions about the textbooks used to learn English in primary and secondary schools, she said that she would like to change the syllabus and better enable it to be made more interesting, specifically, to create and allow more learning time for speaking activities that will develop their speaking skills rather than just focusing on grammatical rules at all times. This will make the students improve their speaking and love English even more.

\section{\#Case 2: Fatima}

Fatima is a senior at the Department of English of the College of Education. She is about to graduate from the college. She speaks English fluently and she has developed almost a British-like native accent. She has been asked about how much she practices her English on a daily basis. She replied that "...the environment in which I practice speaking is often restricted to academic purposes; mostly inside college for communication with teachers who are in the same field. The language used tends to be very limited. Therefore, and in the absence of the activities that encourage [sic] practicing the four basic communicative skills, there is no chance for the full linguistic capacity to be used. As a natural result, it becomes passive, and over the passage of time, forgotten". 
Also, she declared that she wished to have been granted some further, more significant opportunities with her classmates to practice English by saying "classmate friends could be a great privilege and asset to practice speaking the English language only if the desire comes from within them, not by asking them repeatedly to do so". She further elaborated on the same issue by stating that "this potential opportunity represents a privilege I haven't been lucky to have. For a community like ours, I do not get many opportunities, if any at all, if not none, to practice speaking with individuals outside the university environment. It is like being in a complete separate world where I get back to my normal routine life that lacks all kinds of language practices with others around us. One more challenge I face when it comes to speaking is the insufficient background of words related to certain fields, but this can be overcome by dedication and a lot of hard work."

When she has been asked about the strategies she used in order to develop her English speaking skill, she replied by saying "I like to think and deal with almost every situation in my life in English. This has been greatly helpful. Furthermore, I have joined a number of online English groups for foreigners where we keep exchanging audio messages discussing different topics. Honestly, the one thing I must give credit to for being at this level and exhibiting such a good knowledge of English is watching movies. I always try to imitate the way they speak. I write down any phrases that interest me and practice them daily. I surly haven't acquired that language overnight, but by years of watching."

\section{\#Case 3: Alia}

Alia is a freshman student. She has faced many difficulties in learning English at her primary and secondary schools and at university as well. Firstly, at her basic elementary level as well as the secondary or high school level, most of the teachers neglect the teaching of speaking skills. According to her, teachers even spend their time talking in Arabic and they do not give chances for learners to practice speaking in English. Furthermore, listening is also mostly overlooked and instead, teachers focus on teaching grammar. At university, these procedures and patterns of oversight are repeated, but assume another form. The immediate environment at university is equally, if not proportionately more, unsupportive. No one helps to practice English except in classes.

When she has been asked how she has been able to rise to her current level of fluency in English, with the above structural deficiencies taken into account, and what strategies or techniques she used in order to practice her speaking skill, she replied by saying, "I am ambitious to speak English". She has devoted a lot of her time to watch English movies and serial dramas. She always takes the additional step of recording herself when she practices speaking. She said that "when I practice English and due to the lack of people whom we can interact with in English, I resort to create a person in mind to speak with at the time of practicing. Another time, I read loudly to be familiar with the sounds of words and be able to pronounce the words correctly. I think learning English in general gives me the courage to speak with other people".

\section{\#Case 4: Khalid}

Khalid is a junior student. He is confident enough to speak English. He spends all of his time listening to native speakers on Youtube. The environment he lives in is not supportive at all, he declared. Based on his narrative, he keeps trying to find his own virtual world in which to practice English. So, he joined groups on WhatsApp and Facebook. He also loves to add to his ongoing autobiography once a week and share his writings with native speakers of English online. Khalid said that he wishes to have the chance of keeping in contact with native speakers, but the facilities are not continuously available. He said that he was somewhat satisfied with his level of communication in English and all this is due to his practice, the way he speaks to himself, and in front of a wall mirror on occasion.

\section{\#Case 5: Faris}

Faris is a junior student. He said that during the development of his English-speaking competence and in achieving the ability to produce such a notable native-like accent, he faced many difficulties in the process. He believed that he tried to overcome his challenges by devoting a great deal of time for practicing the English-speaking skill. He thought that teachers in elementary as well as secondary schools primarily focused on grammar and vocabulary. They did not give him chances to speak or to speak spontaneously. This is because of the large number of students in each class and the way of teaching adopted by teachers. After finishing his secondary stage of education, he was interested in improving his English. He volunteers that he signed up for English class in an institute and got a diploma from there, describing it as an amazing institute. It was the first step that he initiated in which he was able to overcome the setbacks of learning English in general and the skill of speaking in particular. 
Culturally and socially speaking, learning two different languages or more make the person aware of the world around him/her, such as the cultures of others, traditions and their beliefs which may influence him/her positively. For example, before studying in the institute, Faris volunteered that he did not care about the student timetable, and that he always came late to classes. However, when he joined this institute and learned English, he started to change that bad habit. Additionally, Faris had been accustomed to thinking badly of women when they wanted to complete their studies and help the men in their duties, but after exchanging ideas and opinions with his classmates on debatable and provocative topics organized by the institute, he then recognized that he had evolved to be a more open-minded young adult. The only thing that learning English language cannot have any influence on, Faris concluded, is that of his religious beliefs.

\section{\#Case 6: Ali}

Ali is a sophomore student majoring in English in the college of education. As he wrote in his diary, he said that since the time he had been studying in the secondary school, he invested his time into being a good English communicator. He spent a great deal of his time listening to many British accents. He, faced, and he is still facing, a lot of difficulties in picking up the skill of speaking in an optimal manner, but as he has a large reservoir of determination to draw upon in order to succeed, he accepts all of the associated challenges. The purpose that Ali states he has in his mind is that he has to speak English in the same way the Brits do. He added "I imagine myself like them in many ways and I am doing the best I can to imitate their accent every time I talk and every time I repeated some expressions in English".

In fact, while Ali has expressed his inherent desire to talk exactly like British people, he acknowledges that it does not mean that he has to behave like them or accept their culture as it is. Ali recognizes that he has his own distinct culture, and admits to being very attached to it. He limits his own stated purpose to acquire English and talk fluently as native speakers do. If this purpose is achieved, he would then have the opportunities of getting a good job in his country or abroad. To achieve this aim, he said that "I used different techniques and strategies like listening to audio and visual materials, watching films, YouTube videos, reading magazines, newspapers, novels, interacting with my classmates in class and outside classes. We usually meet each other once a week and having to debate a topic on a certain subject. Another strategy is that sometimes I talk to myself and imagine I am talking to another person on a certain topic. I call it a crazy talk."

\section{\#Case 7: Raqwan}

She is a college senior. She is about to graduate and get her BA in English language. In her diary, she admitted that she has "faced many problems in learning English. Teachers did not give us enough time to practice English. I have a high level of motivation to be a good speaker of English but the circumstances around me did not help me to use English. People don't like others to speak English in front of them. They consider this as an act of showing off. I tried to avoid such a thing in public". When she has been asked what things you do or techniques you utilize to come up with such a good level of speaking competence, she said, "I have determination to invest in other ways to pick up the language and particularly to be a good speaker. I tried to use different strategies and techniques to practice my English. I started watching movies with English and Arabic subtitles. So, I can listen and read at once. I used to write down the new words, phrases, idioms and try to keep by heart from 5 to 10 of them daily along with using and writing them in my own made context. Another strategy I used is that I invented a daily conversation with myself."

Additionally, she commented on the same point by declaring that she tried to imitate exactly the accents she heard in the movies she watched and to practice making the same accent and pronunciation when she practiced speaking English. In order to increase her vocabulary repertoire, she said, "I daily read magazines, newspaper, and novels. It is good to say that anyone who wants to improve his English, he/she must invest his time to practice his language regularly."

\section{\#Case 8: Shifa}

Shifa is a sophomore student in the college of education at the Department of English. She is extremely enthusiastic and motivated to learn English and improve her speaking skill. Upon being asked about the difficulties she has faced in order to improve her English speaking, she said "practicing speaking sometimes seems to be hard for me. But due to the pressed schedule that I have in the college, it is almost impossible to find enough time with my friends to sit and practice speaking. However, I could sometimes manage to find 15 minutes, give or take, to practice speaking either with family or friends." She has similarly experienced that in those random quick conversations, she often repeats the same ordinary words instead of utilizing the more advanced words. She concluded her thought on this aspect by saying that "the environment I live in is not supportive. The language of communication between people is Arabic and even among us as majors in English. 
Therefore, I find myself forced to use my mother tongue to communicate with people around me and instead of making English as part of my lifestyle, it becomes a temporary way of communication."

When Shifa has been asked about the way she persevered in order to develop her speaking skill, Shifa replied "I usually feel unhappy with my level of speaking. To keep myself motivated and to stay away from flat routine, I tried different strategies and techniques to practice English oral communication. First of all, I spend a regular amount of time to watch movies and documentary programs. When watching a movie, I try to grasp as many new words as I can. I write them down in my notes and I use them in sentences. So it becomes much easier for me to memorize all of the words. Moreover, I usually write a summary, describing the series of events in the movies and I include the new words taken from such scenes. Furthermore, I watch English news and documentary programs. The structure of the language and vocabulary words used in such a domain, are very useful in learning how to create an academic piece of writing."

Similar to the previously recorded strategies, this student has used another strategy, which is to write down the words which she frequently hears from her teachers during regular school lectures. She instantly searches for the meanings and saves them in her notebook. Moreover, she has further explained that "I try to practice my speaking skill by making a dialogue with myself or exchanging conversations with my father or sister who happen to speak English in my case. Here, I have to mention that since the time when I was young, wherever I travelled, I was encouraged by my father to not hesitate asking people in English if I needed anything such as ordering food or asking how to get to certain places. Thus, I have got my speaking abilities improved and I was able to overcome the fear of surviving English language dialogues."

\section{\#Case 9: Tahani}

Tahani is a junior student of the Department of English. She is very concerned about her language. She takes every single free moment and step to practice English oral communication. She faced several challenges when she started practicing her English-speaking skill for the first time. She said that most of her classmates at the elementary and secondary levels were taught in English by "unqualified teachers". She continued saying that "this situation affects us negatively by having, for example, fossilized wrong pronunciations of some English words. It was very hard to come up with the correct pronunciation because it has been fixed in my mind for quite a long time since I was studying at the basic education stage".

Another difficulty for Tahani, as she admitted, is that "no one can talk to me in English. If I had a partner, it would have made a fast progress in my speaking proficiency so much easier. Also, the people around me are not of much help to encourage me to practice my English speaking. All these factors play a role in delaying my progress in speaking English fluently. But I do not stop trying different ways in the absence of a conducive environment to find people to talk with. So, I started practicing my English speaking with myself. I tried to talk to native speakers of English through the Internet using chat programs or platforms. In fact, it is not easy. It needs a lot of continuous listening and honest persistence together with the practice. The only source I used is listening. I always listen and watch to tons of movies and TV shows".

After some time, Tahani has become able to orally produce a few words and sentences. The years she spent practicing listening paid off for what she has noticed as the difference in her progress and the ability to express herself more freely in English. She added, “...now I still keep practicing my English speaking through chatting or listening and live the language as if I were in English speaking country."

\section{\#Case 10: Mariam}

Mariam is a senior student. She is an enthusiastic student. She loves English and always uses it. She was asked by the researchers about the difficulties she has been facing in learning English and English speaking in particular. She replied that her "difficulties basically lie in the practice of speaking. The environment in which I live does not encourage me to speak English. In the classroom, I only answered the questions that teachers asked. There are no opportunities to practice English at the elementary school or the high school. When I started my major in English, I set a goal that I should master the English language. Teachers have encouraged me at the university to talk in English. But the time is not enough to master and speak fluently." More importantly, Mariam has declared that she has motivation to achieve her goals, i.e. speaking English like native speaker. In her own words, she said:

"I invest every single moment to practice English. I started to listen to songs, English conversations. Then I watched many English movies. I collected other listening materials related to education and I began listening to them and repeat what I have already listened to. I got many online friends and I always chat with them in English. I have become very confident and I always want to take the initiative and answer some of the questions 
that are usually posed by my teachers in class. I feel happy to get the chance to be involved in class activities such as presentations or discussions. Now, I have my own independent personality to speak up and talk to other people and I feel free to participate in debates organized by the department of English".

\section{Discussion}

The results of this recently completed study have proven to be generally congruent with previously constructed studies and theories in roughly the same research field of identity and L2 learning, L2 motivation and investment, the notion of imagination and imagined communities, and most of the empirical studies and investigations conducted in various L2 contexts have been previously reviewed in this study (cf., Dörnyei, 2001; Norton, 2000, 2001, 2006, 2013; Ramanathan \& Pennycook, 2008; Vygotsky, 1978; Anderson, 1991; Simon, 1992; Moná \& Rodríguez, 2017; Duo \& Su, 2015; Yoshida, 2013). Any casual reader cannot help but be struck by the intense desire and motivations of the cadre of students at the English Department of the College of Education, Seiyoun University, specifically with respect to the lengths they have been ready to go to not only achieve goals that are very difficult for EFL learners with more developed English language backgrounds and available teaching and technological resources, but also to make up for the natural deficits they unfortunately encountered in the paucity of qualified teaching personnel or the opportunities to practice what would become their most important functions to perform, in their formative, biologically most productive years to learn. The juxtaposition of the fervent attempt by these very dedicated students, and the presence of a surrounding culture that sadly seems to be under greater levels of attack with every passing day, along with the interplay between the existence of these two sets of circumstances, provide a very fertile, and quite possibly historically unprecedented, window of opportunity for future researchers to analyze and dissect. We, as researchers, invite any and all future inquiries, and are happy to cooperate with any clarifying questions or comments.

The vertical depth and horizontal width of personal testimony and observations offered in this case study are such that it is truly necessary to additionally examine and review in a holistic manner, and not only to simply address the stated objectives at the outset. In the context of a much broader-based discussion, these specific answers to the research questions will be embedded in a much wider and richer body of quantitative analysis.

From the findings of this study, it was obvious that all of the individual cases in the study have experienced, in varying and existent degrees, some level of personal identity conflicts. Especially, given the current circumstances around the English department at Seiyoun University in Hadhramout, in the Republic of Yemen, it cannot fail to be mentioned that the entire region is in a state of instability which may have both direct and indirect implications and influences on the sample of this study. The students' identity conflicts can be explained merely upon the basis of consternation at the prospect of losing the conflict between their actual identity and the embedded identity that can be found in the targeted language they are attempting to master, which is English. The students' actual identity, which stems from their Islamic and Arabic backgrounds, and which is much more conservative, ethnocentric, and practiced at extreme levels, may actually inspire some in the community to instigate violence against members of other communities who speak the targeted language at a native capacity. It should also be noted that this culture has a particularly high level of tolerance, and, given their historical significance in developing and maintaining important standards within their culture, also carry a great deal of pride and dignity, which translates into a greater degree of tolerance and hospitality towards people who come from diametrically different cultures, as well as the modern capability and tendency to communicate with them online.

The identity conflicts, as shown in the narratives of these ten individual cases, were not directly mentioned, but may be understood from the situations where students are attempting to use different strategies and techniques to avoid adopting or acting like native speakers in public, while privately making use of more clandestine approaches to language learning and/or acquisition for speaking activities, such as inventing imaginary dialogues by themselves, watching themselves speak in front of a mirror, and dissecting the pronunciation of British speakers of English to such an extent that they can conscientiously produce accented English very close to the accents of those that are heard. The construction of these new imagined identities is clear in all of their utterances, and they are migrating towards the potential of having two completely separate identities through imagining various communities. The conflict under study arises from this circumstance.

One factor that is viewed as a contributing factor to the construction of identity is the high level of motivation exhibited by all of the students in the study. The investments they have undertaken to use the language under different circumstances available to them, are extremely noteworthy, and deserving of future considerations in more conventional settings. It must also be noted that, in many of these individual musings, there is revealed a superior level of motivation, to overcome the absence of local teachers or appropriate instruction to guide them 
in their early learning stages of English, and even to a certain extent, an existence in their current educational circumstances. Their obvious zeal and enthusiasm for searching out and finding targeted communities and, in some cases, imagined communities, both online and within their own conscience, speaks to an unusually high level of language investment, language learning motivation and determination to optimize their English identity.

As a final point, it should also be stated that, in the process of intensively formulating, processing and studying for their ultimate goal of attaining a new identity through the use of English, as well as the conflicts emanating from the struggle between the actual practice of speaking English versus the performance of English in front of other members of their culture, as discussed earlier, they are, perhaps subconsciously, constructing a future exodus from the Republic of Yemen as a whole and the Hadhrami land per se, which would effectively dilute, to a certain extent, the culture and identity they have developed over their formative and transitional years, from elementary to secondary levels of education, and continue to this day, in some form, at the university level.

\section{Conclusion}

It can be concluded that there exist some easily measurable conflicts between the targeted language spoken and the actual identity of the students. Several strategies are being used by the students to overcome or eliminate the conflicts between their beliefs, actual identities and the goals they have set for themselves to be good speakers of the target language. We recommend, first of all, that teachers, syllabi and contexts, in light of the findings and results of the study, as well as the textbooks, should promote more authentic speaking activities, as the students themselves have raised during their interviews.

Additionally, family, parental, and societal support should be offered to teachers, to refresh their personal levels of English, and update their probable body of teaching methods and knowledge, in order to deliver a curriculum that better addresses the needs and comprehensive knowledge and skills of contemporary students, as well as to bridge the gap between the actual identities or beliefs exhibited by the students, and the learning outcomes for creative individuals, who could potentially serve both their families and their countries, as a whole.

An important consideration for any student of language should be that they can feel comfortable in acquiring any language without the potential conflict of alienating themselves from the standing culture suggested by their home country. Family support, societal support, and institutional support for this objective should be highly promoted and adapted wherever possible, to enable the current generation of students to be free of these chronicled conflicts, while preserving the actual identities they hold at the time of their language learning or acquisition. In this way, colleges could help to develop more well-rounded graduates who will ideally serve both their immediate society, and the nation of Yemen as a whole.

\section{Acknowledgments}

The authors would like to thank all of the students who have participated in the study, and the College of Education at the University of Seyioun for their dedication and willingness to provide a forum for the students to share their reflections, and provide such insightful narratives that have deepened our current understanding of the phenomena under study.

\section{References}

Alaei, M. M., \& Ghamari, M. R. (2013). EFL Learning, EFL Motivation Types and National Identity: in Conflict or in Coalition. Issues in Language Teaching, 2(2), 85-111.

Al-Tamimi, N., \& Attamimi, R. (2014). Effectiveness of Cooperative Learning in Enhancing Speaking Skills and Attitudes towards Learning English. International Journal of Linguistics, 6(4), 27-45. https://doi.org/10.5296/ijl.v6i4.6114

Al-Tamimi, N., \& Attamimi, R. (2018). Using explicit pronunciation instructions to develop Students' english speaking competencies: A Quasi-experimental Study. International Journal of English Language Teaching, 6(4), 57-73.

Al Yafaei, Y., \& Attamimi, R. (2019). Understanding teachers' integration of Moodle in EFL classrooms: a case study. English Language Teaching, 12(4). https://doi.org/10.5539/elt.v12n4p1

Anderson, B. (1991). Imagined communities: Reflections on the origin and spread of nationalism. London, UK: Verso.

Attamimi, R., \& Abdul, R. H. (2011). Socio-Economic Orientations in Foreign Language Learning Motivation: The Case of Yemen. Asian EFL Journal, 13(4), 167-197.

Dörnyei, Z. (2001). Motivational strategies in the language classroom. Cambridge: Cambridge University Press. 
https://doi.org/10.1017/CBO9780511667343

Duo, P., \& Su, M. (2015). An Investigation of Taiwanese College English Majors' Learning Motivation and Self-Identity Changes. The International Academic Forum, retrieved from http://www.iafor.org

Gómez, C. (2012) Language learners' identities in EFL settings: resistance and power through discourse. Colomb. Appl. Linguist. J, 14(1), 60-76. https://doi.org/10.14483/22487085.3813

Moná, M. C., \& Rodríguez, L. F. G. (2017). The Construction of English Learners' Identity from a Social Perspective and the Effects on their Language Learning Investment. HALLAZGOS, 14(28), 105-122.

Norton, B. (2000). Identity and language learning: Gender, ethnicity and educational change. Harlow, UK: Longman/Person.

Norton, B. (2001). Non-participation, imagined communities and the language classroom. In M. Breen (Ed.), Learner contribution to language learning: New directions in research (pp. 159-171). Harlow, UK: Pearson Education.

Norton, B. (2006). Identity as a sociocultural construct in second language education. In K. Cadman \& K. O'Regan (Eds.), TESOL in Context (Special Issue, pp. 22-33).

Norton, B. (2013). Identity and language learning: Extending the conversation (2nd ed.). Bristol, UK: Multilingual Matters. https://doi.org/10.21832/9781783090563

Pavlenko, A., \& Lantolf, J. P. (2000). Second language learning as participation and the (re)construction of selves.In Sociocultural theory and second language learning (pp. 155-177). Oxford: Oxford University Press.

Ramanathan, V., \& Pennycook, A. (2008). Articulating identities: communities, histories, migrations. TESOL in Context, 18(2), 22-41.

Salazar, L., \& Reyes, C. (2015). Language and Identity Essay. Retrieved March 17, 2019, from https://www.coursehero.com/file/24024546/Language-and-Identity-Essaydocx/

Simon, R. (1992). Teaching against the grain: Texts for a pedagogy of possibility. New York, NY: Bergin \& Garvey.

Vygotsky, L. (1978). Mind in society. Cambridge, MA: Harvard University Press.

Wenger, E. (1998). Communities of practice: Learning, meaning and identity. Cambridge, UK: Cambridge University Press. https://doi.org/10.1017/CBO9780511803932

Yihong, G., Zhao, Y., Ying, C., \& Yan, Z. (2005). Self-identity changes and English learning among Chinese undergraduates. World Englishes, 24(1), 39-51. https://doi.org/10.1111/j.0883-2919.2005.00386.x

Yoshida, R. (2013). Conflict between learners' beliefsand actions: speaking in the classroom. Language Awareness. https://doi.org/10.1080/09658416.2012.7581295yuh5

\section{Copyrights}

Copyright for this article is retained by the author, with first publication rights granted to the journal.

This is an open-access article distributed under the terms and conditions of the Creative Commons Attribution license (http://creativecommons.org/licenses/by/4.0/). 